\title{
A Defence of Sexual Inclusion
}

\author{
By John Danaher, NUI Galway, Ireland \\ Forthcoming in Social Theory and Practice, https://pdcnet.org/soctheory
}

\begin{abstract}
This article argues that access to meaningful sexual experience should be included within the set of the goods that are subject to principles of distributive justice. It argues that some people are currently unjustly excluded from meaningful sexual experience and it is not implausible to suggest that they might thereby have certain claim rights to sexual inclusion. This does not entail that anyone has a right to sex with another person, but it does entail that duties may be imposed on society to foster greater sexual inclusion. This is a controversial thesis and this article addresses this controversy by engaging with four major objections to it: the misogyny objection; the impossibility objection; the stigmatisation objection; and the unjust social engineering objection.
\end{abstract}

Keywords: sexual inclusion; distributive justice; rights; misogyny; stigmatisation; sexual justice

\section{Introduction}

"Sex is not a sandwich" and a "kiss is not a contract" — two quotes that capture received wisdom about the ethics of sex. The former captures the belief that sexual experience is not a good or resource that can be divvied up and shared among many people. The latter captures the belief that, when it comes to intimate interactions with other human beings, we need to nip any sense of sexual entitlement in the bud. No one is entitled to anything when it comes to sex.

\footnotetext{
${ }^{1}$ This quote comes from Srinivasan (2018) but is inspired by an essay originally written by Rebecca Solnit in which the disanalogy between sex and a sandwich is first proposed. See Solnit (2015).

${ }^{2}$ This is the title of a song by the satirical/parodic folk duo The Flight of the Conchords. The meaning of the song is ambiguous. While ostensibly about the nature of consent and the hollowness of casual sexual hook-ups, there are other lines within the song that might speak to male entitlement and justify a casual objectifying attitude towards women.
} 
Both statements are ethical common sense and although this paper does not reject either claim, it does seek to moderate them to some extent. It does so by arguing for two theses. First, it argues that sexual experience (in the sense of both partnered and non-partnered sexual experience) is a good that can be evaluated in light of the principles of distributive justice. In other words, it argues that having access to meaningful sexual experiences is an important part of the good life, that some people are unjustly sexually excluded, and that we ought to think about this as a problem of distributive justice (or injustice, as the case may be). Second, it argues that thinking about sexual experience in these terms provides some justification for the idea that there is a 'right', or more properly a collection of positive and negative claim rights, to sexual inclusion. In other words, those who are unjustly sexually excluded may, under certain circumstances, have a right to have measures taken on their behalf to assist their sexual inclusion. This does not mean that they have a 'right to have sex' with other people — or that other people have a duty to have sex with them — but it does mean that steps should be taken to give them a reasonable opportunity to access meaningful sexual experiences. This can take the form of removing barriers to meaningful sexual experience (such as legal bans on certain forms of sexual expression) and facilitating positive sexual experiences (through, for example, education or technological aid).

This article is not the first to defend or debate claims of this sort. There is, for example, a long-standing debate within the disability rights literature about the sexual exclusion of persons with disabilities and the possibility that they might have a right to sexual inclusion (Shakespeare 1999, de Boer 2014 \& 2015, Appel 2010, Di Nucci 2011 \& 2017 \& 2019, Thomsen 2015 and Liberman 2018, Firth 2019). There is also a long-standing strand within feminist theory that is deeply sceptical of any suggestion of rights and 
entitlements to sex, largely on the grounds that patriarchal ideology already contains within it the belief that men have (or should have) a sexual claim right over the bodies of women and that this needs to be resisted (Pateman 1988, Jeffreys 2008, Manne 2018, ch 4, Srinivasan 2018).

This article wades into these debates with some trepidation. It does so in the hope that it can build upon the existing literature in three important ways. First, by presenting an argument for sexual inclusion that does not limit itself to the concerns of particular sub-sets of people but focuses on the general problem of sexual exclusion and what ought to be done about it. Second, by resisting the temptation to slide too quickly and unjustifiably into talk about sex rights. And third by engaging with the major counterarguments and objections to the idea of sexual inclusion.

The paper proceeds in three stages. In the next section, it presents an initial defence and explanation of what it might mean to treat sex as a distributive good. This is followed by an initial defence and discussion of what it might mean to say that there can be both positive and negative claim rights to sexual inclusion. Then, with these initial clarifications out of the way, the paper proceeds to the main task of addressing and responding to objections to its two theses. It address four major objections (The Misogyny Objection; The Impossibility Objection; The Stigmatisation Objection; and the Social Engineering Objection) as well as a handful of more minor objections. The paper concludes by arguing that the two theses remain compelling and significant despite the fact that there are legitimate concerns about how they might work in practice.

\section{Sexual Experience as a Distributive Good}


The first thesis defended in this article is that sexual experience can be (and ought to be) treated as a distributive good, i.e. as something that people should be able to experience as part of a well lived life and that ought to be thought of in light of the principles of distributive justice. What case can be made in favour of this thesis?

Let's start with the general idea of distributive goods and distributive justice. Most people are familiar with the thought that wealth and material resources can be understood as distributive goods. If a society generates a social surplus of material wealth, then we typically accept that a decision needs to be made about how that social surplus ought to be distributed. There are morally better or worse ways of doing this. A world in which all the material wealth flows to one individual would obviously be unjust (unless there is only one person in the world) whereas a world in which all wealth was shared equally would probably be just (though we need to be careful since this may require unjust transfers of wealth and may compromise other aspects of social well-being). In between those two extremes, there is plenty of room for reasonable disagreement about how to distribute material wealth in the fairest and most just way. Some people are avowed minimal statists, resistant to most wealth transfers; some people are radical egalitarians, insisting on significant transfers from the wealthy to the poor; some people are prioritarians or luck egalitarians, insisting that some people deserve transfers and others don't and that there should be a priority ranking when it comes to accessing the social surplus. The debate is complex and this is worth bearing in mind when it comes to thinking about sexual experience as a distributive good.

But why think of sexual experience as a distributive good? There are two points to make in response to that question. The first point is that, although material wealth might be the natural home for distributive thinking, there are 
other things, including experiences and opportunities, that can appropriately feature among the distributive goods that are part of our theory of distributive justice. Various goods like education, health, and the enjoyment of cultural products are, for example, already widely discussed in these terms. Another example, which provides an illustrative analogy for present purposes, is meaningful work. Paid employment is a source of income. If people lose their jobs, we often immediately think about the need to compensate them for the loss of income this entails. This is natural distributive justice thinking. But work is a source of other goods too. It is a source of meaning, purpose and social status. Recently, several authors have argued that we need to think about these nonincome-related goods in distributive terms as well (Gheaus and Herzog 2016; Timmerman 2017; Bowie 2018). For example, Cristian Timmerman has argued that the good of meaningful work is currently unfairly distributed and that this ought to be corrected. In making this argument, Timmerman focuses specifically on the experiences that are part and parcel of being employed, and not just the material benefits it brings. The reason why people think about experiences like meaningful work, the enjoyment of health and well-being, and the enjoyment of culture in distributive terms is straightforward. These experiences are integral to the good life. They are part of what it means to live a rich and flourishing life.

This leads to the second point. The obvious reason to treat sexual experience as a distributive good is that it too is part of what it takes to live a rich and flourishing life. Sexual experiences (if done right) are intrinsically pleasurable and enjoyable; they also have great personal and cultural significance. Having a sex life is usually taken to be part of what it takes to be a mature member of society. So much so that some people don't feel themselves to be fully human in its absence (de Boer $2014 \&$ 2015). It would, consequently, not be too much of a stretch to say that having a sex life is part of what it takes to live a meaningful 
and purposeful life, and so should be included in the package of 'goods' that make up our theory of distributive justice. Of course, this thought should not be pushed too far. Some people can choose to be celibate for religious reasons, others find that they have low sex drives and are contentedly asexual by nature. These people can live perfectly happy and fulfilling lives. For many, however, the absence of sex is a struggle and, at a minimum, it seems reasonable to suggest that everyone should be given the opportunity to have a sex life.

These thoughts are not original. Tracy de Boer, for example, has argued we should think about the importance of sexual experience in light of Martha Nussbaum and Amartya Sen's 'capabilities' approach to justice (De Boer 2014, ch. 2; Nussbaum 2011 and Sen 1999). The essence of this approach is that justice should not be seen exclusively in terms of material wealth and resources but, instead, in terms of opportunities to live a flourishing life. De Boer argues, reasonably enough, that having access to a sex life is core to what many people see as a flourishing life and so sexual opportunity should be part of the capabilities approach to justice (De Boer 2014, 33-34). Likewise, Di Nucci has argued that even if sex is not necessary to well-being it is at least a very important element of well-being for many people such that its 'nonvoluntary absence from someone's life would be morally relevant' (Di Nucci 2017, 75).

These will be obvious claims to some readers, but this then prompts the question: Why is it that meaningful sexual experience and access to a meaningful sex life have not featured widely in debates about distributive justice to date? ${ }^{3}$ Indeed why is it that the thought that they ever could has been treated with great suspicion? This article opened with Rebecca Solnit's claim

\footnotetext{
${ }^{3}$ One notable exception to this is the utopianist plan of Charles Fourier which proposed a guaranteed sexual minimum - somewhat akin to a guaranteed basic income. Fourier's proposal is, of course, deeply problematic given the authoritarianism and coercion it would seem to entail. A rich amorous nobility, according to Fourier, would be required to service the sexual needs of the masses. On this, see Srinivasan 2018.
} 
that sex is not like a sandwich. The intention behind this claim was to argue that sex should not be thought of as something that can be divided up and redistributed from the sexually enriched to the sexually impoverished (Solnit 2015). The merits of this criticism will be dealt with later on, but now simply note that some of this suspicion might derive from what we take the good of sexual experience to be. If we can clarify what it is that we are trying to distribute more fairly, we can see whether or not it is absurd to think about its distribution in terms of the principles of distributive justice.

In this respect, it is important that we are not too narrow or traditional in our definition of meaningful 'sexual experience'. If you assume that what it takes to have a meaningful sex life is to regularly engage in penile-vaginal intercourse then, of course, the notion that sexual experience is a distributive good that ought to be thought of in light of principles of distributive justice will seem absurd. Not only that, it will be obviously wrong since it excludes meaningful homosexual sexual experiences from its calculus. Penile-vaginal intercourse is one form of meaningful sexual experience, but not the only form. We need to go beyond the bounds of tradition to generate a plausible conception of sexual justice.

When we do this the concept of meaningful sexual experience becomes necessarily tricky to define. But we can embrace this fuzziness. In doing so, we can acknowledge that different sexual experiences can be meaningful to different people, depending on both the nature of their sexual preferences, and the nature of their sexual inclusion/exclusion. Any reasonable theory of sexual justice must take heed of this pluralism. At a minimum, sexual experience would require some degree of sexual arousal and pleasure (up to and including orgasm), but since people can get their kicks in different ways it is hard to be more precise than that. It is plausible to assume that for many people sexual 
experiences are most meaningful when they involve a sexual partner (or partners), but ensuring that everyone has access to a sexual partner is certainly not required by a reasonable theory of sexual justice. Enabling people to access pleasurable forms of masturbation, for example, could be very beneficial and meaningful to them if they have been prevented from access this themselves. Similarly, having access to various sex technologies, including sex robots (Di Nucci 2017), could be part of our conception of meaningful sexual experience. Broadening our conception of sexual experience in this manner makes thinking about it in distributive terms more reasonable.

Two important caveats should be borne in mind when adopting this pluralistic approach to meaningful sexual experience. First, the good of sexual experience often gets entangled with other related goods, such as intimacy and a sense of maturity. We can live with this entanglement and, indeed, use it as part of the argument for thinking about sexual experience as a distributive good, provided we don't conflate the good of sexual experience with these other goods. Sexual intimacy is but one form of intimacy - important though it may be - and the other forms of intimacy should not be neglected in our distributive calculations. Furthermore, there are other pathways to a sense of maturity that could be as beneficial as accessing a sex life. It is important that the sex-specific goods be kept front and centre in any theory of sexual justice. Second, although this article urges a pluralistic approach to meaningful sexual experience, it is essential to the view being defended that certain forms of sexual experience are not 'on the table' when it comes to applying distributive principles to the problem of sexual exclusion. For example, if someone has a sexual preference for otherwise immoral sexual experiences - e.g. nonconsensual sex or sex with a child - then this cannot and should not be factored into any plan to create a more sexually equal world. 
Should we care about creating a more sexually equal world? To answer that question we need to engage with the problem that motivates this entire article: the problem of sexual exclusion. This problem arises from the fact that some people are being limited or excluded from meaningful sexual experience and so are living a less rich and flourishing life than others. Not all such people should concern us. As noted, there are presumably some people that have voluntarily excluded themselves from sexual experience. Their lack of a sex life does not suggest that something is amiss when it comes to our overall sense of how just our society is. Nevertheless, there are others who are unjustly sexually impoverished or excluded, who lack access to a meaningful sex life and who experience that lack acutely. These are the people that should concern us and should encourage us to think about the idea of creating a more sexually equal world.

To understand why, we need to get a bit clearer about the potential mechanisms of sexual exclusion. Although many of these mechanisms overlap in individual cases, and although it is dangerous to group them into distinct conceptual categories, for initial purposes we can identify three main mechanisms of sexual exclusion:

(i) Personal, i.e. mechanisms of exclusion that stem from the properties or features of the person who is excluded. Examples might include a person's prejudicial attitudes toward certain, otherwise available, sexual partners, a person's sexual shyness or awkwardness or their excessive romantic idealism, and certain (but definitely not all) physical or mental disabilities that the person might have.

(ii) Social, i.e. mechanisms of exclusion that stem from the properties or features of other people (other than the person who is sexually excluded) or 
social institutions. Examples might include prejudicial attitudes toward the social group to whom the excluded person belongs (e.g. presumptions of asexuality for disabled persons; anti-trans beliefs etc), laws and social norms that prohibit or condemn certain sexual liaisons (e.g. laws criminalising homosexual and interracial sexual activity), and discriminatory ideologies.

(iii) Natural, i.e. mechanisms of exclusion that result predominantly or exclusively from evolved instincts or drives that lead people to favour certain kinds of sexual partner or sexual experience over others.

It needs to be reiterated, lest there be any confusion, that dividing up the mechanisms of exclusion in this way has the potential to mislead. It is essential that we don't assume that the distinctions between them are precise or that any individual case of sexual exclusion is likely to fit wholly or neatly within one of them. On the contrary, most actual cases will involve the 'intersection' of multiple mechanisms of sexual exclusion. The categories are merely for the purposes of bringing some preliminary order to how we think about this topic. It is also worth noting, in passing, that the suggestion there is a clear category of 'natural' mechanisms of sexual exclusion, that is distinct from social mechanisms, is rejected by some people. This is mentioned now because it is relevant to one of the objections (the Social Engineering Objection) discussed later in this paper.

Are any of these mechanisms of sexual exclusion unjust? Presumably yes. If you are homosexual and prevented from accessing meaningful sexual experiences due to laws that criminalise your sexual conduct, then you are being unjustly excluded from meaningful sexual experience. This is an easy case. Other cases are trickier but it is possible to see injustice within them too. Take a potentially controversial example: that of an obese man. In our present day and 
age, obesity is sometimes seen as a sexually unattractive quality; it is also something that can, in its extreme form, make it physically difficult to engage in sexual activity. Assume that this obese man is unable to find a sexual partner or engage in satisfactory sexual experiences. Is he being unjustly sexually excluded? Possibly. We know that norms of beauty and sexual attractiveness are variable to some degree - pleasant plumpness was historically a sexually attractive quality ${ }^{4}$ and norms of body size and shape do vary cross-culturally ${ }^{5}$ thus it seems plausible to think that the man is a victim of unjust exclusion due to the, at least somewhat, contingent and arbitrary variations in social norms (cf. Minerva 2016 and 2017 who discusses the wider injustices perpetuated by this form of 'Lookism'). As a result of this unjust exclusion, we might think it appropriate to do something to improve his sexual opportunities. We could do this by changing the prejudicial attitudes of those around him, by making it easier for him to link up with people who find his body shape and size sexually desirable or, perhaps in certain circumstances, even paying for gastric-bypass surgery to reduce body size. This last suggestion will be controversial so it is important to clarify that physical body modification is very unlikely to be the preferred means of resolving unjust sexual exclusion. In general, if someone has a body shape/property that is widely (though not absolutely) perceived as sexually unattractive there will be three things we can do to address their sexual exclusion: (i) we can do something to modify their body shape or property; (ii) we can match them to those who find their body shape attractive (or give them access to other outlets for sexual expression that are non-partnered, e.g. sex toys

\footnotetext{
${ }^{4}$ Ancient artifacts of female body types are often plump or obese by modern standards. Also the depiction of ideal female body types in art and fashion has changed over time. The so-called 'Rubenesque' beauty based on the paintings of Peter Paul Rubens - does not seem to fit the ideal of beauty in the modern era. For an excellent analysis of changing ideals in female waist-to-hip ratio over time see Bovet and Raymond 2015. Of course, it is noteworthy that the example used in the text is of an obese man, not a woman, and that beauty standards have always been somewhat more flexible for men (at least in heterosexual communities).

${ }^{5}$ For a general discussion see Swami and Furnham (2007). A particularly controversial example of variation in cross-cultural beauty standards is that of Mauritania where 'overfed' women are seen as sexually desirable. For a description of the overfeeding practice, see Ouldzeidoune et al 2013. For an attempted explanation of why desired weight varies cross-culturally, see Anderson et al 1992. I am indebted to an anonymous reviewer for drawing my attention to the Mauritania example.
} 
and so on); or (iii) we can try to change societal preferences to make them more sexually included. In the majority of cases, strategies (ii) and (iii) are most likely to be the 'just' strategies to follow because they will not involve some permanent body modification nor will they compound the injustice done to an already marginalized/excluded population by making the problem something that they need to 'fix'. That said, this does not mean that (i) is never the appropriate thing to do. There could be cases in which it is morally justified due to reasons of cost-effectiveness or triviality, consent, and the fact that other moral ends are satisfied in the process. So, for example, some countries already pay for gastric bypass surgery as part of national healthcare on grounds of personal health and well-being. The fact that it might also facilitate sexual inclusion could be part of the justification for doing this and does not, if the argument in this paper is correct, need to be denied or occluded from the discussion (though, on this point, see the discussion of the Stigmatisation Objection, below).

Similarly, imagine the case of a heterosexual woman who rarely or never experiences an orgasm, either through masturbation or with a sexual partner. This is not an uncommon problem. Researchers find that there is an 'orgasm gap' between heterosexual men and women, with heterosexual women experiencing one third fewer orgasms than heterosexual men, according to one largescale study (Frederick et al 2018). Is this woman a victim of sexual injustice? Possibly. She may live in a society in which women's sexual pleasure is not taken seriously and is subordinated to male sexual pleasure (a common concern), or she may never have been taught about how to adequately sexually pleasure herself. There are things we as a society could do to ensure she has more equal access to pleasurable sexual experiences. Indeed, people are already 
talking about the need to close the 'orgasm gap' in these egalitarian terms (Horan 2018; MysteryVibe 2018). ${ }^{6}$

We could go on and consider other examples involving the unjust sexual exclusion that arises from disability (de Boer 2014 \& 2015; Shakespeare 1999) or transgender sexual exclusion (Sharpe 2018), but the point is made: some forms of sexual exclusion are unjust and unfair and there are things we could do to mitigate this injustice.

Our perception of injustice in these cases probably depends on two major variables: (i) whether we think there is anything we, as a society, can do to rectify the problem of exclusion (without causing significant damage to other moral values/rights and at a reasonable cost) and (ii) to what extent we blame the individual for their own plight. If we think there is something we can do, and we don't blame the individual for their sexual exclusion, we are more likely to perceive an injustice. When the opposite is true, we are more likely to shrug our shoulders and tell people to help themselves. It's possible that neither of these variables should influence our perceptions of injustice, but for the purposes of this article we can remain neutral on this matter.

In sum, the preceding discussion should suffice for a prima facie argument in favour of thinking about meaningful sexual experience as a distributive good. Some people are impoverished and excluded from this good, and some of them are excluded and impoverished for unjust or unfair reasons. What's more, people are already thinking about these cases of in light of the ideals of distributive justice. They are just not doing so systematically and explicitly. They are focusing on particular cases of exclusion and not on the general phenomenon. This article urges us to take the more general perspective and

\footnotetext{
${ }^{6}$ Also, for example, see https://www.salon.com/2018/06/02/the-orgasm-gap-picking-up-where-the-sexualrevolution-left-off_partner/
} 
focus on sexual exclusion per se as a key issue (Liberman 2018). It also urges us to think about this first and foremost in terms of distributive justice - i.e. as something to be addressed through principles and ideals of equality - and not primarily as a rights-related issue.

Still, we have to spend some time considering the idea of sex rights since it features so prominently in the debate about sexual inclusion and exclusion (e.g. De Boer 2014 \& 2015; Appel 2010, Di Nucci 2011, Thomsen 2015, Liberman 2018, Srinivasan 2018). That's what we do in the next section.

\section{A Right to Sexual Inclusion}

Recognising sexual experience as a distributive good does not entail or require us to recognise the existence of sex rights. ${ }^{7}$ It is possible to recognise that something is integral to a well-lived human life without necessarily endorsing the idea that each and every individual has a right to some fair share of it. For example, many societies recognise that money and property are important distributive goods without at the same time recognising an individual right to a specific share of money or property. Ensuring a fair share of those goods is seen as an aspirational social goal, not a juridical right. Still, it is important not to be disingenuous in making this point. Recognising something as a distributive good does provide moral grounds for recognising potential rights to a fair share of that good. This is because individuals have a moral interest or stake in distributive goods and this is commonly taken to provide a normative grounding for rights. So in recognising sexual experience as a

\footnotetext{
${ }^{7}$ It should be clear from this sentence that I am not relying on a 'natural' or 'moral' theory of rights in this paper. I'm focused on legally recognised and operational rights. I assume there is a connection between ideal morality and the recognition of a right, but that there is also some 'gap' between what might be morally ideal and what is legally wise.
} 
distributive good we do start down a path that leads, quite naturally, to talk of sex rights.

Before we go too far down that path, however, we need to emphasise that certain kinds of sex rights should never be entertained. For example, a right for one person to have sex with a specifically identified other person, without any care for that other person's rights and entitlements, would be morally abhorrent. It would not, unfortunately, be historically unprecedented - in many countries, until quite recently, husbands effectively had a (negative) right to coerced intercourse with their wives due to the so-called 'marital rape' exemption — but we should not return to such a world, nor should we think that recognising sexual experience as a distributive good requires such a return. Before recognising a right to anything in particular you need to consider the different moral interests, costs and benefits at stake, and weigh them appropriately. This may speak against the recognition of a right, even if there is a morally legitimate interest at stake.

Taking this onboard, the remainder of this section defends the view that recognising some kind of right to sexual inclusion is not necessarily an implausible or absurd consequence of viewing sexual experience as a distributive good. Or, to express the same thought more positively, it is argued that there are some compelling moral reasons to favour recognising a bundle of both positive and negative claim rights to sexual inclusion.

There is much room for confusion or misunderstanding here so it is important to clarify exactly what is being said. Let's start by clarifying the nature of rights. The word 'right' is multiply ambiguous. As noted long ago by Wesley Hohfeld (1919), when people refer to the idea of a 'right to x' they often conflate and confuse distinct moral claims and powers. In his more recent 
updating of Hohfeld's analysis, Leif Wenar $(2005 ; 2012)$ argues that rights break-down into four distinct 'incidents' or 'molecular' components: (i) the privilege, i.e. the freedom to do as you please within a certain zone of privacy; (ii) the claim, i.e. the duty imposed on others to do or forebear from doing something to you; (iii) the power, i.e. the legal entitlement to waive your rights; and (iv) the immunity, i.e. the legal protection against others trying to waive your rights on your behalf. These four incidents are conceptually and logically related. Recognising that someone has a privilege to do X usually entails a corresponding claim-right against others to recognise that privilege and not to interfere with the exercise of it. Still, it is possible for the different incidents to pull apart and not be recognised conjointly. Most alleged 'rights' are not any one thing but rather bundles of these different incidents.

So what kind of a right might a right to sexual inclusion be? The most obvious classification would be as a claim-right, i.e. as a claim that a sexually excluded person can make against others to do or forebear from doing something that will ensure their greater sexual inclusion. It could also, in some cases, be a privilege, i.e. a freedom to engage in certain kinds of sexual activity without interference - though it should be remembered that any such freedom would have to be balanced against the rights and freedoms of others, and would have to factor in other moral costs. For the most part, we will ignore the idea of privileges in what follows and focus on claim-rights to sexual inclusion.

Note how the plural form ('claim-rights') was used in the previous sentence. This is because the right to sexual inclusion should not be understood as a single type of claim that one person can make against another. Rather, it should be understood as a bundle of different moral claims that a sexually excluded person might be entitled to make. An analogous example would be the "right to a fair trial'. This right is not any one specific thing but, rather, a bundle of different 
rights that an accused person has, including the right to legal counsel, the right to confront one's accusers, the right to an impartial tribunal, the right to silence, the presumption of innocence, the right to a jury of one's peers, and so on. Some elements of this bundle of rights are more important than others, and some are downplayed and ignored in some jurisdictions; nevertheless, they all go into the general idea of a right to a fair trial. The right to sexual inclusion will be broadly similar, consisting in a bundle of more and less important claimrights.

In viewing the right to sexual inclusion as a bundle of claim rights, we need to introduce another important conceptual distinction. This is the distinction between positive claim-rights and negative claim-rights. This distinction was flagged in the earlier definition of a claim-right but it is important to spell it out. A positive claim-right is a duty that one person can impose on another to do something on his or her behalf. For example, a positive claim-right to housing or education might impose a duty on a government to provide an individual with housing or education. A negative claim-right is a duty that one person can impose on another to refrain from interfering with his or her exercise of a privilege. For example, a negative claim-right to private property would impose a duty on others not to trespass or interfere with that property. The bundle of claim rights to sexual inclusion could feature either type.

This is enough by way of clarification. Why should we accept the idea that there is such a bundle of claim rights? There are two reasons: (i) recognising at least some claim-rights to sexual inclusion is morally justified and (ii) doing so does not entail any significant moral (or other) costs. In other words, recognising such rights would be the humane and decent thing to do, in light of the importance of meaningful sexual experience to the well-lived life, and in 
response to the fact that some people are unjustly excluded from that kind of experience.

The best way to argue for this is by considering specific examples. We can start by looking at negative claim-rights to sexual inclusion. Many negative claim-rights to sexual inclusion are plausible because recognising them entails no significant moral costs. All it usually requires is removing legal restrictions on certain kinds of sexual activity. This then unlocks meaningful sexual experience for large cohorts of people. One could argue that many of the historical struggles for sexual justice have taken this form. For example, removing criminal and other legal bans on homosexuality and interracial relationships is both an explicit and implicit recognition of a negative claimright to sexual inclusion.

That said, not all negative claim-rights to sexual inclusion are going to be uncontroversial. In the literature on disability and sex rights, there is an active and ongoing debate about removing legal restrictions on prostitution and sexual surrogacy in order to enable certain disabled people to access meaningful sexual experience (De Boer 2015; Appel 2010; Di Nucci 2011; Thomsen 2015; Liberman 2018). Those who favour removing such restrictions do so on the grounds that they are an impediment to sexual inclusion. The counterargument is that legalising prostitution and sexual surrogacy is not morally costless. There are problems with both forms of work that could be exacerbated through legalisation. A similarly controversial debate arises in relation to negative claim rights to the sexual inclusion of transgender persons. In some countries it is effectively a criminal offence for a transgender person to have sex with someone without disclosing their gender history. Some scholars see this as an unjust form of sexual exclusion (Sharpe 2018). The counterargument to this is that the failure to disclose gender history infringes on the negative sex rights of 
other people to consensually choose their sexual partners. No judgment is passed on either of these controversies in this article but note that they are being, and can be, debated in a way that vindicates the general plausibility of negative claim-rights to sexual inclusion: proponents of greater sexual inclusion are identifying what they perceive to be unjust impediments to inclusion, and opponents are highlighting the moral costs of removing those impediments.

Now let's consider positive claim-rights to sexual inclusion. Again, it seems obvious that many such rights will be plausible. For example, a positive right to sex education, including education about different mechanisms of female and male sexual pleasure, would be one way to ensure greater sexual inclusion (e.g. to close the heterosexual orgasm gap), and would seem to be relatively morally costless (though, of course, socially conservative groups may disagree). Similarly, a positive right to the provision of sex aids and sex toys might also be a way to foster greater sexual inclusion, particularly for those who otherwise lack the resources to obtain them. A positive claim-right to anti-discriminatory education and training could also be a way to address sexual inclusion, in a manner not that dissimilar to the existing rights provided under antidiscrimination law. For example, Tracy de Boer has argued that one of the biggest impediments to sexual inclusion for disabled persons is the tendency for people to view them as asexual and not take their sexual needs seriously (De Boer 2014 and 2015). Educating people, particularly carers and health professionals, about those needs would be a relatively costless way to address sexual exclusion.

Again, not all positive claim-rights to sexual inclusion will be uncontroversial. It bears repeating that a positive claim-right to sexual intercourse with another person would be morally abhorrent and should not be countenanced. But nothing in the case for a right to sexual inclusion requires 
that we endorse that idea. Still, other less blatantly problematic, positive claim rights could have hidden or subtle costs that might make their recognition less normatively compelling. For example, it might be too difficult or economically costly to provide certain forms of sex aid or sex education, and some people might see the latter as a kind of unwarranted 'brainwashing'. Some of these concerns will be considered below, but their potential existence should not discourage us from taking seriously the idea that there could be at least some rights to sexual inclusion. Indeed, the recognition of at least some such rights seems to be, prima facie, plausible and morally compelling.

The only thing that might disrupt this conclusion (and the previous one about recognising sexual experience as a distributive good) is the existence compelling objections to the entire idea of taking seriously the problem of sexual exclusion. Let's now consider a series of such objections and determine whether they are, in fact, compelling.

\section{The Misogyny Objection}

Let's start with the 'Misogyny Objection'. This objection is rooted in feminist writings about male-female sexual relations. Carole Pateman (1988), in her book The Sexual Contract, spoke out about the idea of the male 'sex right' which she saw as something that was inherent to patriarchal gender relations. Her idea was that under conditions of patriarchy men can have or perceive themselves to have a de facto claim-right to the sexual use of a woman's body. This is something that can be reinforced by the existence of actual juridical rights too, such as the aforementioned exemption from marital rape. Sheila Jeffreys has used this idea to explicitly critique the discussion of disability rights and sexual exclusion (Jeffreys 2008; de Boer 2015). The worry seems to be that discussions of 'unjust' or 'unfair' sexual exclusion tend to prop up and 
reinforce patriarchal gender relations and that women will tend to be unfairly treated under any system of 'sex rights'.

The glib response to this concern is to say that nothing in the preceding discussion of sexual exclusion and inclusion favours or reinforces the idea of male claim-rights to the sexual use of female bodies. Quite the contrary. The analysis in the previous section was at pains to dismiss this as something that is morally abhorrent. Furthermore, the discussion to this point has been gender neutral: it assumes that both men and women (and non-binary persons) can be victims of unjust sexual exclusion. Hence there is nothing in the prima facie case for a right to sexual inclusion that suggests that men will be greater beneficiaries of it at the expense of women.

But this is a glib response because it doesn't take onboard a more nuanced understanding of misogyny and patriarchy, nor does it consider how discussion of the injustice of sexual exclusion and a right to sexual inclusion could help to reinforce this. To develop a more nuanced understanding of the problem, we can turn to Kate Manne's analysis of misogyny from her 2018 book Down Girl. In this book, Manne develops a careful, 'ameliorative' analysis of misogyny and how it relates to patriarchy and sexism. She dismisses what she calls the 'naive' view of misogyny as a form of psychological and individualised hatred towards woman (Manne 2018, chapter 1), and favours a more contextual and socialised understanding of the phenomenon (Mann 2018, chapter 2). In rough outline, Manne argues that patriarchy is the set of social institutions (norms, laws, beliefs and practices) that tends to favour male dominance and female subordination; that sexism is the ideology that undergirds those institutions (Manne 2018, chapter 3); and that misogyny is the set of practices that enforce the norms of patriarchy by keeping women 'down' (Manne 2018, chapter 2). 
Although Manne believes that misogyny can take different localised forms (depending on the society and history in question), she argues that a core substantive part of misogyny is its role in enforcing and policing female giving and male taking. She argues that, under conditions of patriarchy, women are expected to perform certain moral support roles for men: they are expected to give men things like care, admiration, attention and, crucially for present purposes, sex (Manne 2018, 130). Men assume or demand that women do these things for them and shame, ridicule, question, undermine, gaslight and, ultimately, punish women who violate those expectations. Crucially, however, Manne argues that misogyny doesn't always manifest itself in violence and coercion. Indeed, because the goal is to prop up a system in which women perform support roles for men, the preference is often for 'soft power' mechanisms of enforcement. Women are rewarded for performing the support roles and encouraged to see themselves as givers of care, sex, admiration and attention. This is seen as core to their 'femininity'. It is only if they step out of line that more coercive methods of enforcement are used.

Manne gives many real life examples of how misogyny, so defined, manifests itself. Two of them are particularly relevant for present purposes because they involve expectations around female sexual giving. The first example is Elliot Rodger (Manne 2018, ch $1 \&$ 4). Elliot was a member of the online 'incel' community. ${ }^{8}$ In May of 2014 he killed six people and injured fourteen others in a rampage shooting in Santa Barbara, California. According to his online manifesto/memoir and a video that he published shortly before the killings, he did this because he felt sexually excluded and humiliated by certain kinds of women (he tried, but failed, to kill members of a sorority at UCSB). He

\footnotetext{
8 'Incel' is short for 'involuntary celibate'. That said, the identity label has a much richer set of connotations. Members of the incel community often define themselves in opposition to feminist ideals and in favour of a certain understanding of masculinity. For a longer analysis of the incel community and its associated beliefs, see Ging 2019.
} 
specifically said that he felt "cast out and rejected, forced to endure an existence of loneliness and insignificance, all because the females of the human species were incapable of seeing value in me" (Srinivasan 2018).

The second example is Rush Limbaugh and the comments he made about Sandra Fluke - a young law student who argued before the US congress that birth control should be covered by health insurance for women at religious institutions. Limbaugh was incensed at the idea that taxpayers should fund Sandra Fluke's sex life. If this was going to happen, he argued that there should be something in it for him (and the other taxpayers), namely access to amateur pornographic videos of Sandra Fluke having sex:

"... if we are going to have a part in this, then we want something in return, Ms Fluke: And that would be the videos of all this sex posted online so we can see what we are getting for our money."

(Limbaugh, quoted in Manne 2018, 57)

As Manne notes, both men exude significant amounts of sexual entitlement (Manne 106-107). They assume that women ought to be servicing their sexual needs, or, in the case of Limbaugh, giving them some sexual quid pro quo.

Manne's analysis of misogyny gives us what we need to construct a more nuanced version of the Misogyny Objection. This more nuanced version holds that any talk of sexual exclusion and of rights to sexual inclusion - even if it explicitly disavows the idea of a male claim-right to the sexual use of a woman - will still take place in a patriarchal social order in which women are expected to be sexually giving towards men. It will layer itself on top of this patriarchal order and be interpreted and practiced in its shadow. Misogynistic norm 
enforcement will then get to work and create mechanisms - not necessarily punitive - that support the expectation of female sexual giving. In this manner, the idea of the male sex right will find an implicit lease of life. This is one thing that greatly worries Amia Srinivasan (2018) in her discussion of sex rights and sexual exclusion. Although Srinivasan is sensitive to the plight of some people who are sexually excluded, and thinks we may need to bring greater political and ethical scrutiny to the discriminatory nature of our sexual preferences, she worries that doing so will provide the cloak for sexual entitlement and claim rights to the bodies of others:

"there is a risk too that repoliticising desire will encourage a discourse of sexual entitlement. Talk of people who are unjustly sexually marginalised or excluded can pave the way to the thought that these people have a right to sex, a right that is being violated by those who refuse to have sex with them."

(Srinivasan 2018)

This is one reason why Srinivasan thinks it is best not to think of sexual experience as distributive good, but rather as something that is sui generis and totally different from anything else we value and share.

This is certainly a more persuasive and subtle way to run the Misogyny Objection, but is it any good? The objection should be taken seriously, but it does not suffice to undermine the idea of treating sexual experience as a distributive good, nor the plausibility of some rights to sexual inclusion. What the Misogyny Objection shows is that the project of ensuring greater sexual inclusion is fraught with risk and that, if done wrongly, could serve to reinforce a discriminatory and oppressive social regime. But in and of itself this is not enough to scupper the project. Most moral projects and revolutions are fraught 
with risk. They can clash with or exaggerate the worst features of the old regime. The project of ensuring greater racial equality, for example, has historically had to layer itself on top of social norms, beliefs and practices that were inherently racist. This has had some unwelcome manifestations (e.g. the Jim Crow system in the southern US), but this did not mean that the project itself should have been abandoned. It just meant that more work needed to be done (and still needs to be done) to overcome the legacy of racism.

The same is likely to be true when it comes to sexual inclusion. If there is a genuine injustice in sexual exclusion, then it is important that we address that injustice even if doing so is fraught with risk. In this respect it is important to remember that there are different types of sexual exclusion, not all of which are unjust, and that sexual exclusion often overlaps and intersects with other forms of discrimination and social exclusion. Some people face far more profound and systematic forms of sexual exclusion than others. As noted already, some disabled people find that their sexuality is completely denied or ignored (de Boer $2014 \&$ 2015). They aren't just excluded from pleasurable or desirable forms of sex; they are excluded from all forms of sex. This compounds and reinforces the other kinds of discrimination that they face. Likewise, heterosexual women are often themselves victims of systematic and repeated sexual exclusion: their sexual pleasure is often not taken seriously, as is evidenced by the existence of the orgasm gap, and any project of sexual inclusion should be focused on them just as much, if not more so, than anyone else.

The answer to the Misogyny Objection, therefore, is not to deny the injustice of sexual exclusion, but rather to build in significant anti-misogyny safeguards to how the project of sexual inclusion is pursued. Although this is something that will require greater development, there would appear to be four key 
elements to those anti-misogyny safeguards. First, the commitment to a strong zone of negative sexual autonomy should be reiterated and emphasised at every opportunity. No one should feel obligated to sexual activity against their will. The right to refuse sexual interactions should take pride of place in any schema of sex rights. Second, priority could be given to addressing certain forms of sexual exclusion over others. In particular, priority could be given to those who experience more profound and systematic forms of sexual exclusion, and who find that their sexual exclusion intersects with other forms of discrimination and exclusion. By granting such priority, we can better guarantee that the project of sexual inclusion supports and reinforces other social justice and equality projects. Third, we need to recognise and emphasise that some forms of sexual exclusion are not unjust; they are the product of immoral minds and/or immoral social norms. In this regard, the sexual exclusion experienced by someone like Elliot Rodger is not something that should be recognised by a theory of sexual injustice. It is the result of misguided, sexist, though sadly not uncommon, beliefs about what a 'real' man should expect and desire in the way of a sexual partner (Ging 2019). We do not have to legitimise or validate those sexual preferences (just as we don't have to legitimise or validate the sexual preferences of the rape fantasist or paedophile). Finally, and in light of this, we should recognise that misogynistic beliefs and practices are themselves often the cause of sexual exclusion, both for men, who demand and expect unrealistic forms of sex, and for women, whose sexual needs and desires are ignored. Thus, dismantling and reforming misogynistic beliefs and practices can be seen as part and parcel of the project of fostering more sexual inclusion. They need not be in tension with one another

\section{The Impossibility/Impracticality Objection}

The second major objection is the Impossibility Objection (or, less severely, the Impracticality Objection). According to this objection, the project of 
fostering a more just distribution of sexual experience is doomed to fail because it is morally or practically impossible to realise. There are different ways of running this objection. Some focus on what seems to be a genuine practical or maybe even conceptual impossibility in the idea of sexual inclusion; others focus on the ineffectuality or resource costs that might be involved.

An example of what might be a serious moral or practical impossibility can be found in the work of Ezio di Nucci and his 'puzzle' about sex rights (2011). Di Nucci's puzzle arises from thinking about rights to partnered sex. He argues that there is a tension between the recognition of positive and negative rights to partnered sex. As he puts it:

"Universal positive sexual rights are incompatible with universal negative sexual rights. If $A$ has a positive sexual right, then that means that there is at least one person who would lack negative sexual rights. Namely: the person who would be supposed to fulfill A's positive sexual rights." (Di Nucci 2011, $159)^{9}$

Di Nucci is surely correct in suggesting that there is significant tension between positive and negative claim rights to partnered sex. But since the incompatibility only applies to partnered sex, it does not undermine the argument being made in this article: this article has already been at pains to argue that we should not recognise a positive claim right to partnered sex. Furthermore, Di Nucci himself thinks it would be 'bad' if we concluded, from his formulation of the puzzle, that there are no positive sex rights (Di Nucci 2017, 73). Still, his puzzle does prompt a broader inquiry into whether there might frequently be tensions between positive claim rights to sexual inclusion

\footnotetext{
${ }^{9}$ Strictly speaking, positive and negative sex rights are not metaphysically incompatible. It is possible to imagine a world in which everyone's positive desire for sex with another is not contradicted by anyone's negative desire to avoid sex with another. It's just highly implausible that we live in such a world.
} 
and other negative rights. For example, could it be that one person's claim right to be recognised as a sexual being is in tension with another person's right to freedom of thought?

This is superficially plausible, but the mere fact that there might be some tension between a positive right to sexual inclusion and some other negative claim right is not a reason to deny the existence of the positive claim right. Positive and negative rights often come into conflict and the conflict isn't always resolved in favour of the negative right. For example, my negative claim right to my own property need not take precedence over your positive claim right to retreat to my property to protect yourself from violent attack; my negative right to do as I please with my time might not take precedence over your positive right to demand that I give evidence at your trial.

What matters really are the moral interests and costs at stake. If it would be worse, all things considered, to favour a negative right over a positive right, then we may wish to recognise the positive right to the detriment of the negative right. This could be true in the case of rights to sexual inclusion. As noted earlier in this article, some positive rights to sexual inclusion are relatively low cost (in terms of the moral stakes at play). They focus on the right to enlightened sex education, the right to have one's sexuality recognised and the right to technological sex aids and birth control. While recognising such rights may involve the violation of someone's negative rights, the violation would be relatively minor and costless. Di Nucci recognises this himself by arguing that the provision of sex robots would be one, less morally costly way, to recognise positive sex rights (Di Nucci 2017). Furthermore, in response to criticisms from Steven Firth (2019), Di Nucci (2019) has clarified that his original formulation of the incompatibility did not imply that positive sex rights were completely impossible. On the contrary, his view is that we should be open to the idea that 
there are positive sex rights, provided that they do not interfere with anyone's negative rights to sexual self-determination. This would seem to imply that a positive sex right can interfere with other kinds of negative rights (e.g. such as the right to property and so on).

There are other ways to run the objection. These do not focus on moral or physical impossibilities but rather on how difficult or ineffectual the recognition of rights to sexual inclusion would be in practice. For example, we might doubt whether enlightened sex education could actually do much to change people's sexual attitudes and behaviours. Or we might worry that the provision of sex aids to people who are sexually excluded is insulting and only gives them access to a less meaningful or desirable form of sexual experience. Or we might worry that providing such education and services comes with a significant opportunity cost. A critic could point out that there are more pressing issues of distributive justice that need our time and attention. The problem of sexual exclusion is too difficult to solve and not worth the time and energy.

None of these concerns is sufficient to scupper the project of fostering greater sexual inclusion. Part of the argument made in this paper is that we currently underestimate and underappreciate the problem of sexual exclusion. This is because of an inconsistency in our moral beliefs. Most of us recognise that meaningful sexual experience is part of the good life, but we don't think seriously about the systematic and enduring exclusion of certain groups of people from meaningful sexual experience. We don't appreciate that there are simple things we can do to help these people. These things may seem trivial or ineffectual from the perspective of someone who doesn't experience this form of exclusion, but they may be quite significant from the perspective of someone who does. Furthermore, as suggested above, we shouldn't think about social justice projects as zero-sum games. Resolving the problem of sexual exclusion 
need not come at the expense of other kinds of distributive social justice. Since sexual exclusion often overlaps with and intersects with other forms of discrimination and inequality, addressing it can help to reinforce and compound our other efforts to create a more just society. Finally, we need to bear in mind the old saying that we shouldn't make the perfect the enemy of the good. Just because recognising certain positive rights to sexual inclusion may seem tantamount to recognising inferior or less meaningful form of sexual experience does not mean that recognising them brings no net benefit. This is true for other forms of distributive justice too. Giving someone a welfare payment of $€ 200$ a week is better than giving them nothing, even if it doesn't make them a millionaire. Why should we take a different attitude toward the distribution of meaningful sexual experience?

\section{The Stigmatisation Objection}

The third objection is the Stigmatisation Objection. This objection holds that trying to foster sexual inclusion is deeply problematic because it risks stigmatising and exacerbating the social exclusion experienced by certain groups of people. The clearest exponent of this objection is probably Alida Liberman (2018). She focuses specifically on how the problem manifests in the debate about disability and sexual exclusion. Liberman argues that focusing on the sexual exclusion of disabled persons is misleading and problematic because being disabled is neither necessary nor sufficient for being sexually excluded (Liberman 2018, 255). She argues that the term 'disability' is vague and covers many different people with many different conditions. Some of them may experience sexual exclusion, but many others will not. Furthermore, many people who do not have disabilities will experience sexually exclusion so that focusing solely on the sexual exclusion of persons with disabilities will obscure or distract from the wider problem. As Liberman puts it: 
"Focusing on disability status as a proxy for sexual exclusion both perpetuates negative stereotypes about disability, and is a less fruitful approach than getting to the core of the issue by focusing on sexual exclusion directly."

(Liberman 2018, 256)

Although Liberman does not develop this point, it seems obvious that her concern transfers over others group of people one might like to focus on because of their sexual exclusion. This includes other groups discussed in this article, such as heterosexual women, obese persons, transgender persons, geeky introverted men and so on. If you make a special issue of their sexual exclusion you risk stigmatising and perpetuating negative stereotypes, particularly negative sexual stereotypes, about an entire group of people.

Two things can be said in response to this objection. First, note that Liberman herself thinks that the solution to the problem is to focus on sexual exclusion per se and not on other proxy variables that might happen to correlate with sexual exclusion. That's exactly the case that this article is putting forward: that we should make an issue out of sexual exclusion itself and shouldn't assume that it is a problem faced by only one cohort of people. We should appreciate its pervasiveness and seriousness beyond particular niches or subsets of humanity. So this article is, in part, trying to make the corrective move that Liberman recommends. ${ }^{11}$

But this might seem a little disingenuous. After all, the way in which sexual exclusion overlaps and intersects with other kinds of discrimination and social

\footnotetext{
${ }^{11}$ It should be noted that Liberman herself is somewhat circumspect about the problem of sexual exclusion. She isn't sure how seriously it should be taken or what should be done in response to it (Liberman 2018, 256).
} 
exclusion has been emphasised throughout. And it was argued that people who experience unjust sexual exclusion in addition to other forms of unjust social exclusion should be given some priority in any scheme of distributive sexual justice. If this position is followed in practice it would seem to entail the stigmatisation and 'othering' that concerns Liberman, perhaps in a more balkanised and extensive form.

This is where the second response to the Stigmatisation Objection comes in. It may be that singling out particular groups is, unfortunately, an inevitable but necessary consequence of any approach to distributive justice that tries to be sensitive to intersecting dimensions of exclusion and discrimination. If you are sexually excluded and disabled and transgender, then you may well experience a unique compounding set of unjust exclusions. It is not clear why we shouldn't want be sensitive to that unique set of experiences in our approach to distributive justice. And it's not clear why it wouldn't be appropriate to prioritise or pay special attention to your kind of case. We do this in other distributive contexts already. For example, when it comes to educational opportunities and scholarships, there doesn't seem to be anything untoward about setting up a scheme that gives priority to working class women from racial minorities. Indeed, you might even argue that a scheme that ignored those interlocking dimensions of identity would be less just than one that did not. If one of the forms of injustice experienced by, say, trans people is their sexual exclusion (in addition to other forms of injustice) ignoring that and lumping their experiences in with other groups who experience sexual exclusion for different reasons, may be tantamount to silencing or overlooking the unique nature of the injustice suffered by transgender person. This would then perpetuate the unique injustice they suffer. 
This doesn't mean that we should not be vigilant against the risk of stigmatisation. The risk is real whenever we mark out some group of people as being 'different' from everyone else. We should do our best to combat the stigma and potential shame around unjust sexual exclusion (just as we should combat the stigma and shame around other forms of unjust impoverishment such as the frequent stigmatisation of those in poverty). In short, we should be alert to the potential double-stigmatisation that Liberman highlights, but in being alert to this risk we may still find it necessary to recognise that some groups experience sexual exclusion in unique and special ways. We should do this by encouraging empathy and sympathy, not hostility and shame.

\section{The Social Engineering Objection}

The fourth objection is the Social Engineering Objection. This objection holds that the project of fostering greater sexual inclusion should be rejected on the grounds that it would require a dystopian, fruitless and possibly unjust exercise in social engineering. There are at least two different ways of running this objection.

The first way will be particularly appealing to those who think there are certain 'hard' natural limits to the malleability of our sexual drives and preferences. Proponents of evolutionary psychology, for example, might argue that male and female sexual psyches have evolved to desire certain kinds of sexual experience and certain kinds of sexual partner (Buss 2003; Eisenman 2006; Fleischman 2018). To use the common view (as it applies to heterosexual persons): men have evolved to desire young-ish, fertile-looking women and are very keen on casual sexual encounters; women have evolved to want slightly older, more financially stable men who will nurture and care for children. This is revealed through actual sexual behaviour and practice, even if it is denied by 
the people who engage in those practice. Furthermore, even though our cultures are quite removed from the original context in which these sexual psyches evolved, and there is noticeable cultural variation in sexual beliefs and practices, these evolved psyches still exert a gravitational pull. They limit what it is possible to change through social reform. As one proponent puts it, specifically in response to claims by feminists and social progressives about reforming pornography and sex technology, people "underestimate the degree to which evolved psychology, rather than culture or technology, shape [sexual] attitudes" (Fleischmann 2018).

There are several things to be said in response to this version of the objection. For starters, it should be noted that the evolutionary psychology theory of sexual behaviour is highly contested, and there are many criticisms of the research findings that are supposed to support the theory (Prinz 2012; Dupre 2001; Buller 2005). This is not the place to litigate the debate about these findings. ${ }^{12}$ We can simply note the controversy and the fact that its existence means some people won't be inclined to take this objection seriously. But if we accept the theory, and believe that there are natural limits to the malleability of sexual desire, this should not lead us to reject the ideal of fostering greater sexual exclusion. One reason for this is that we can foster greater sexual inclusion without having to reengineer people's evolved sexual preferences and desires. Oftentimes, fostering greater sexual inclusion is as simple as removing unjust legal barriers to sexual activity. Other times it is just about educating people to make the best use of their evolved sexual psyches, e.g. through learning how to maximise or optimise their own sexual pleasure and the pleasure of their partners. Providing technological aids, including sex toys and

\footnotetext{
${ }^{12}$ For what it is worth, my view is that some of the findings are weak and relatively unpersuasive. But this is true of many findings in psychology, as the recent replication crisis has revealed. Nevertheless, I think some findings are fairly robust and have held up well under repeated scrutiny. For example, the finding that men (on average and in most contexts) are more willing to engage in casual sexual encounters than women, seems to be fairly robust. For an extensive review of the research literature on this particular finding see Schmitt 2017.
} 
robots, to the sexually excluded is another way to foster their inclusion without conflicting with evolved preferences. Indeed, Diana Fleischmann, who believes that there are some strict evolved limits to the malleability of sexual desire, sees sex robots as a potential way to address problems of perceived sexual exclusion, particularly among men (Fleischman 2018). She does not express this argument in moral terms, but others, such as Di Nucci (2017) have defended the idea in moralistic terms. Another reason for rejecting the argument is that even if fostering greater sexual exclusion does require some social reengineering of sexual preferences, it is not clear that it would push it beyond the natural limits. There is already a rich diversity to human sexual interests and practices - as the existence of innumerable sexual fetishes reveals - so it is possible that there is more room to play with than we might first suppose. Providing means by which people with those unusual fetishes could find one another might be part of the project of sexual inclusion. It could also be that through deliberate conscious effort and training some people can reengineer their sexual preferences to match moral values in ways we did not think possible. ${ }^{13}$ Finally, it should be noted that some natural limits could be overcome through biotechnological tinkering with our sexual psyches. We already do this to some extent - e.g. through suppressing sexual urges with the use of so-called 'chemical castration' - and it is possible that we will be able to do it to a greater extent in the future. Of course, whether we should do it depends on whether biological tinkering of this form is morally justified. That is a topic that lies beyond the scope of this article.

\footnotetext{
${ }^{13}$ An anonymous reviewer highlighted an episode of the Invisibilia podcast which discusses the extent to which it is possible to change our sexual preferences and recounts the story of a young woman who has tried to hack her racial preferences in dating so that they match closer with her moral values. See Invisibilia Episode 'A Very Offensive Rom-Com', $5^{\text {th }}$ April 2019, available at https://www.npr.org/programs/invisibilia/710046991/a-veryoffensive-rom-com?t=1574953721220. This is an interesting case study and I would encourage readers to listen to this episode.
} 
This brings us to the second way of running the Social Engineering Objection. You don't have to be an evolutionary psychologist to worry about socially reengineering someone's sexual preferences, beliefs and practices. As Amia Srinivasan (2018) points out, a core tenet of an enlightened liberal (sex positive) approach to sex is that, to a large extent, an individual's sexual preferences are their own business. They want whatever it is that they want. If that means they exclude some people from the ambit of sexual experience, then who are we to question it? Anything goes in the bedroom, as long as it is consensual. If we tried to tinker with or alter people's sexual preferences, beliefs and practices to make them more inclusive, we would be unjustly violating their sexual autonomy.

Several of the responses to the evolutionary psychology argument are apposite once again. Fostering greater sexual inclusion does not necessarily entail unjust social engineering of this sort: we don't have to force people to find others sexually attractive when that's not what they want. We can foster greater sexual inclusion by enabling people to work with the sexual preferences, beliefs and desires that they have. But we should also be reluctant to assume that we can never justly question or challenge someone's sexual preferences, beliefs and desires. We already do this to some extent — we don't tolerate the sexual preferences of the rapist or paedophile - and there is no reason to think we shouldn't do it a little more. Again, as Srinivasan points out, if we treat sexual preferences as unquestionable and axiomatic givens then we:

“...risk covering not only for misogyny, but for racism, ableism, transphobia, and every other oppressive system that makes its way into the bedroom through the seemingly innocuous mechanism of 'personal preference'." (Srinivasan 2018) 
Calling these preferences into question doesn't mean forcing people into sexual encounters against their will, but it does mean encouraging them to take a more critical, reflective attitude toward their own sexual psyches and not treating them as sacred, axiomatic truths. There is a role for enlightened sex education here. This is a position that has already been defended in the literature on sexual preferences and race. For example, Zheng (2016) argues that a racial preference for Asian women is objectionable, even when it stems from purely aesthetic preferences as opposed to some racist ideology. Similarly, Mitchell and Wells (2018) argue that it is possible to reconcile the claim that racial exclusions in dating are morally undesirable with the view that people are generally justified in choosing their dating partners as they see fit. In doing so they argue that there are moral reasons to encourage people to change their dating preferences if they are racially exclusive. These arguments focus on the link between racism and sexual/intimate partner preferences, but the analysis can, presumably, be broadened to cover other forms of unjust sexual exclusion. If so, then this reinforces the argument being made in this paper: there are compelling moral reasons to work towards greater sexual inclusion in attitudes.

That said, we have to make sure we do not engage in an unjust and unfruitful form of brainwashing in the process. This might be one place where it is important to think about the precise scope of any positive claim right to sexual inclusion. An excluded person might have a positive right to have sex education classes include the information pertaining to the malleability of sexual preferences and the problem of sexual exclusion, but this does not imply nor should it be taken to imply that they have a positive right to demand that someone else find them sexually attractive. ${ }^{15}$

\footnotetext{
${ }^{15}$ This is analogous to the argument made by Firth (2019) about the distinction between a right to demand funding for sexual services versus a right to demand those services.
} 


\section{Other Miscellaneous Objections}

These four objections would seem to be the major ones. Are there any others that should give us pause? Possibly. There is, for example, Amia Srinivasan's concern that sexual experience is a sui generis phenomenon that cannot and should not be analogised to other distributive goods. She makes this point by discussing the 'sex is not a sandwich' example that was raised in the introduction to this article. As she puts it:

“...whereas you can quite reasonably demand that a group of children share their sandwiches inclusively, you just can't do the same with sex...Sex isn't a sandwich, and it isn't really like anything else either. There is nothing else so riven with politics and yet so inviolably personal. For better or worse, we must find a way to take sex on its own terms." (Srinivasan 2018)

This is an appealing line of thought. It encourages us to treat sexual experience as a unique part of human life. But it can be resisted. No analogy is perfect. All distributive goods are slightly different from one another. Money is not like education and education is not like healthcare, at least not in all respects. But they share enough in common to make thinking about them in terms of distributive justice appropriate. The same is true of sexual experience. It is an important part of a flourishing human life. Some people are given more sexual opportunities than others. Some are unjustly excluded. It makes sense to think about how we can ensure greater equality of sexual opportunity. It is, of course, absurd to think that we can demand that people share sexual experience with others (as they might share a sandwich) but at the risk of sounding like a broken record, recognising a right to sexual inclusion does not require this. 
Another objection that might give us some pause has to do with the practical consequences of recognising that some people are not unjustly sexual excluded and that some of the unjustly excluded should have priority over others when it comes to the distribution of relevant goods and services. Both of these points have been relied upon above when responding to other criticisms. But some people might worry that this will encourage us to divide the world up into the deserving and undeserving sexual poor, and to undertake intrusive investigations into people's lives to see whether they really are unjustly sexually excluded and in need of some assistance.

This is a serious concern. It is, however, a not uncommon problem. It also arises with the distribution of other socially important goods and services (e.g. welfare payments and healthcare). It's not clear that the mere fact that it could arise is enough to discourage us from taking the problem of sexual exclusion seriously. Still, it would be regrettable if we made our distributive system more intrusive and challenging for people suffering from multiple forms of social exclusion. Fortunately, many of the measures that are entailed by recognising a right to sexual inclusion need not entail the intrusive surveillance and investigation of already vulnerable populations. Removing bans and criminal restrictions on certain kinds of sexual activity can be done without any of this; and providing enlightened sex education (and certain kinds of sex aid and sex toy) is something that can be mainstreamed and thereby benefit everyone (just as consent classes and anti-discrimination classes can help everyone). The provision of specialised sex aids and sex toys, and specialised forms of sex education, might be different, but presumably these could work on top of existing forms of benefit provision for the relevant target populations and need not entail additional investigation or surveillance. 
There may be other unintended consequences that result from taking the problem of sexual exclusion seriously. It is hard to imagine them all up front. Constant vigilance and scrutiny will be required to ensure that any scheme for fostering greater sexual inclusion is achieving its desired ends. This is true for all schemes of distributive justice. Perhaps schemes for sexual inclusion are fraught with more risks and warrant greater vigilance but this should not dissuade us from pursuing them.

\section{Conclusion}

In conclusion, it is appropriate to view sexual experience as a distributive good that can be evaluated in light of the principles of distributive justice. Some people are unjustly excluded from meaningful sexual experience and it makes sense to think about what we can do to ensure greater equality of sexual opportunity. Furthermore, the recognition of some bundle of rights to sexual inclusion is a plausible inference from this distributive view of sexual experience. There are several important objections to both of these claims, but none of them is sufficiently serious to scupper the entire project of fostering greater sexual inclusion. At most, they give us reason to pursue that project with caution and vigilance.

Let us close by addressing one final criticism of the thesis presented in this article. Some people might worry that in defending the idea of sexual inclusion an implausibly delicate balancing act has been undertaken. For example, the potential reasonableness of rights to sexual inclusion has been defended by pointing out that we have already, implicitly, been treating sexual experience as a distributive good and reforming our legal systems so as to foster greater sexual inclusion (e.g. by reforming laws on the criminalisation of homosexuality; birth control provision etc). This has been a core part of the 
rhetorical strategy — to suggest that what has been argued is not unprecedented or unusual. Furthermore, by responding to criticism, it has been suggested that the project of sexual inclusion can be pursued in a way that avoids ethical pitfalls and risks. But the worry might be that in the effort to make the project reasonable it has become uninteresting. It has been killed through excessive qualification and caution. In the end, it turns out that there is nothing new or fresh in the idea because all the potentially controversial implications have been disavowed.

But is that a fair criticism? Although the reasonableness of the thesis has been stressed, it has not been stripped it of all its novelty. For one thing, a more explicit and direct engagement with the problem of sexual exclusion has been urged, which thereby highlights a neglected and important desideratum in any theory of justice. It has been argued that distinct debates about disability, sexual orientation, transgender rights, and feminism can all be unified and explained by a common underlying concern for greater sexual inclusion. Furthermore, the kinds of positive and negative claim rights that form part of the right to sexual inclusion are not meaningless or tokenistic. They can make a genuine difference to many people's lives and change how we think about the substantive content of distributive justice.

\section{References}

Anderson, J., Crawford, C., Nadeau, J. and Lindberg, T. (1996). Was the Duchess of windsor right? A cross-cultural review of the socioecology of ideals of female body shape. Ethology and Sociobiology 13(3): 197-227

Appel, JM (2010). Sex Rights for the Disabled? Journal of Medical Ethics 36: 152-154 
Bovet, Jeanne and Raymond, Michel (2015). Preferred women's waist-to-hip ratio variation over the last 2,500 years. PLoS One 10(4):e0123284

Buller, David (2005). Adapting Minds: Evolutionary Psychology and the Persistent Quest for Human Nature. Cambridge, MA: MIT Press.

Buss, David M (2003). The Evolution Of Desire: Strategies of Human Mating. New York: Basic Books.

De Boer, Tracy (2014). Disability and Sexual Justice. MA Thesis, University of Victoria - available at https://dspace.library.uvic.ca/bitstream/handle/1828/5510/de\%20Boer_Tracy_ MA_2014.pdf; sequence $=1$ (accessed 1/2/2019)

De Boer, Tracy (2015). Disability and Sexual Inclusion. Hypatia 30(1): 6681

Di Nucci, Ezio. (2011). Sexual Rights and Disability. Journal of Medical Ethics 37: 158-161

Di Nucci, Ezio (2017). Sex Robots and the Rights of the Disabled. In Danaher, J. and McArthur, N. (eds) Robot Sex: Social and Ethical Implications. Cambridge, MA: MIT Press.

Di Nucci, Ezio (2019). Sexual rights puzzle: resolved? Journal of Medical Ethics http://dx.doi.org/10.1136/medethics-2019-105642 
Dupré, John (2001) “The Evolutionary Psychology of Sex and Gender" in Human Nature and the Limits of Science. Oxford: OUP.

Eisenman, Russell (2006). Evolutionary Psychology Insights Regarding Human Sexuality. Europe's Journal of Psychology Vol 2(4), available at https://ejop.psychopen.eu/article/view/290/html

Firth SJ. (2019). Whither a Welfare-Funded 'Sex Doula' Programme? Journal of Medical Ethics http://dx.doi.org/10.1136/medethics-2018-105330

Fleischman, Diana (2018). Uncanny Vulvas. Jacobite Magazine 24 ${ }^{\text {th }}$ April 2018, available at https://jacobitemag.com/2018/04/24/uncanny-vulvas/

Frederick, DA, St John, HK, Garcia, J, and Lloyd, EL (2018). Differences in Orgasm Frequency Among Gay, Lesbian, Bisexual, and Heterosexual Men and Women in a U.S. National Sample. Archives of Sexual Behaviour 47(1): 273288

Gheaus, A., \& Herzog, L. M. (2016). The goods of work (other than money). Journal of Social Philosophy 47(1): 70-89

Ging, Debbie (2019). Alphas, Betas, and Incels: Theorizing the Masculinities of the Manosphere. Men and Masculinities 22(4): 638-657

Hohfeld, Wesley (1919). Fundamental Legal Conceptions as Applied in Judicial Reasoning. New Haven: Yale University Press.

Horan, Niamh (2018). 'The orgasm gap...and why it's a more pressing issue than the gender pay gap' The Irish Independent $2^{\text {nd }}$ December 2018. 
Jeffreys, Sheila (2008). Disability and the Male Sex Right. Women's Studies International Forum 31(5): 327-335

Liberman, Alida (2018). Disability, sex rights and the scope of sexual exclusion. Journal of Medical Ethics 44: 253-256.

Manne, Kate (2018). Down Girl: The Logic of Misogyny. Oxford: OUP.

Minerva, Francesca (2016). The Invisible Discrimination Before Our Eyes. Bioethics 31(3): 180-189.

Minerva, Francesca (2017). How should we tackle financial and prosocial biases against unattractive people?. Brain and Behavioral Sciences 40: e36

Mitchell, Megan and Wells, Mark (2018). Race, Romantic Attraction and Dating. Ethical Theory and Moral Practice 21 (4):945-961

MysteryVibe (2018). The Orgasm Gap: what is it, and why does it exist? $2^{\text {nd }}$ August 2017, Medium - available at https://medium.com/@mysteryvibe/theorgasm-gap-what-is-it-and-why-does-it-exist-f953ad79d845

Nussbaum, M. (2011). Creating Capabilities: The Human Development Approach. Cambridge, MA: Harvard University Press.

Ouldzeidoune, N., Keating, J, Bertrand, J and Rice, J (2013). A Description of Female Genital Mutilation and Force-Feeding Practices in Mauritania: Implications for the Protection of Child Rights and Health. Plos One, 8(4): e60594, available at https://doi.org/10.1371/journal.pone.0060594 
Pateman, Carole. 1988. The Sexual Contract. Cambridge: Polity.

Prinz, Jesse (2012) Beyond Human Nature. London: Penguin Allen Lane.

Schmitt, David (2017). What Type of Person Would Agree to Have Sex With a Stranger? Psychology Today $28^{\text {th }}$ June 2017, available at https://www.psychologytoday.com/us/blog/sexual-personalities/201706/whattype-person-would-agree-have-sex-stranger

Sen, A. (1999). Development as Freedom. Oxford: Oxford University Press.

Sharpe, Alex (2018). Sexual Intimacy and Gender Identity 'Fraud'. London: Routledge.

Shakespeare, Tom (1999). The Sexual Politics of Disabled Masculinity. Sexuality and Disability 17(1): 53-54

Solnit, Rebecca (2015). Men Explain Lolita to Me. Literary Hub 17 December 2015.

Swami, V and Furnham, A (eds) (2007). The Body Beautiful: Evolutionary and Sociocultural Perspectives. London: Palgrave MacMillan.

Bech-Sorensen, Jens and Pollet, Thomas (2016). Sex Differences in Mate Preferences: a Replication Study, 20 Years Later. Evolutionary Psychological Science 2(3): 171-176 
Srinivasan, Amia (2018). Does Anyone Have the Right to Sex? London Review of Books 22 March 2018.

Thomsen, FK (2015). Prostitution, Disability and Prohibition. Journal of Medical Ethics 41: 451-459

Timmerman, C. (2017). Contributive Justice: An Exploration of the Wider Provision of Meaningful Work. Social Justice Research DOI 10.1007/s11211017-0293-2

Wenar, Leif (2005). The Nature of Rights. Philosophy and Public Affairs 33(3): $223-252$

Wenar, Leif (2012). The Nature of Claim-Rights. Ethics 123: 202-229.

Zheng, Robin (2016). Why Yellow Fever Isn't Flattering: A Case Against Racial Fetishes. Journal of the American Philosophical Association 2(3): 400419 